Results: Overall, 283 patients were included in the register starting SB4 and 369 with oETN. Another 355 patients who had already been enrolled in RABBIT switched to SB4 during follow up. Compared to oETN patients, those enrolled with SB4 had slightly lower disease duration (8 vs. 9 years) and significantly fewer patients had three or more comorbidities ( $40 \%$ vs. $47 \%, p=0.04) .88 \%(n=250)$ of patients enrolled with SB4\% and $86 \%(n=317)$ enrolled with oETN were bionaive. Out of all patients who started SB4 during follow up, $40 \%$ had been treated with oETN, and $39 \%$ with another biologic before switching. $21 \%$ had received csDMARD or no drug treatment before treatment start. Kaplan-Meier curves show comparable retention rates over 6 months for SB4 and oETN (figure 1). Adjusting the curves for disease duration and comorbidities had no significant influence on the results. $8 \%(n=20)$ of bionaive SB4 patients and $17 \%(n=54)$ of bionaive oETN patients stopped treatment during the first 90 days. Additional $6 \%(n=14$, SB4)/ $15 \%(n=46$, oETN $)$ stopped the treatment within 180 days after enrolment. The reasons for discontinuation of both treatments were adverse events (AE) in $59 \%$ $(n=20$, SB4 $) / 49 \%(n=49$, oETN $)$ and loss of response in $26 \%(n=9, S B 4) / 31 \%$ $(n=31, o E T N)$. The most common cause for discontinuation within 180 days due to $\mathrm{AE}$ were skin reactions at the injection site in 35\% (7 of 20) of SB4, and $49 \%$ (24 of 49 ) of oETN patients).

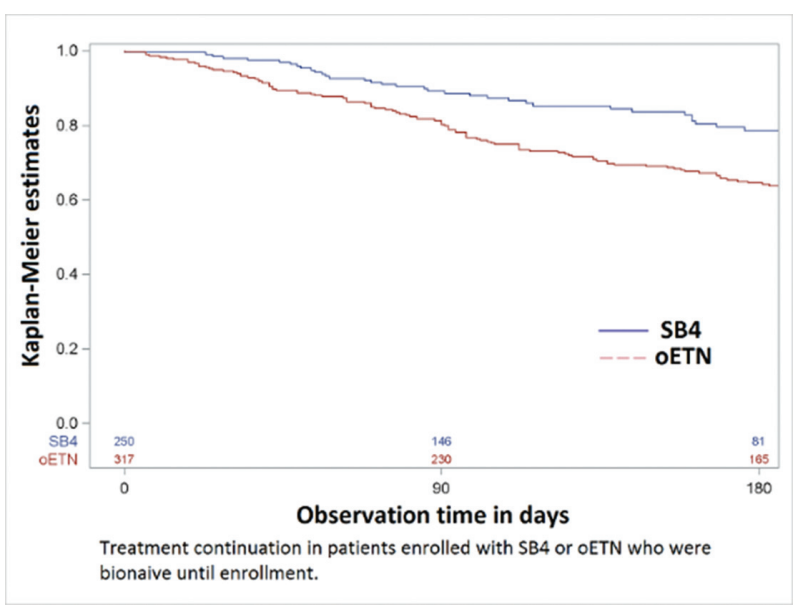

Abstract THU0192 - Figure 1. Treatment continuation in patients enrolled with SB4 or oETN who were bionaive until enrollment.

Conclusions: The retention rates for bionaive patients starting either the biosimilar SB4 or the originator oETN were similar. The distribution of adverse events was also comparable. A selection bias cannot fully be ruled out since patients on oETN had more comorbidities.

Acknowledgements: Disclosure: RABBIT is supported by a joint, unconditional grant from AbbVie, Bristol-Myers Squibb, Celltrion, Hexal, Lilly, MSD Sharp and Dohme, Pfizer, Roche, Samsung Bioepis, Sanofi-Aventis und UCB.

Disclosure of Interest: A. Strangfeld Speakers bureau: AbbVie, BMS, Lilly, MSD, Pfizer, Roche and UCB, L. Baganz: None declared, P. Herzer Speakers bureau: Pfizer, J. Braun: None declared, A. Gräßler: None declared, A. Zink Speakers bureau: BMS, Lilly, Pfizer, Roche, UCB

DOI: 10.1136/annrheumdis-2018-eular.5231

\section{THU0193 EFFICACY AND SAFETY OF BCD-055 (INFLIXIMAB BIOSIMILAR) IN RHEUMATOID ARTHRITIS. RESULTS OF BCD-055-3/LIRA PHASE 3 CLINICAL STUDY}

A. Lila', L. Denisov ${ }^{2}$, T. Plaksina ${ }^{3}$, S. Smakotina ${ }^{4}$, E. Kunder ${ }^{5}$, N. Soroka ${ }^{6}$, A. Kastanayan ${ }^{7}$, O. Nesmeyanova ${ }^{8}$, O. Antipova ${ }^{9}$, E. llivanova $^{10}$, A. Eremeeva $^{11}$, E. Dokukina ${ }^{11}$, E. Chernyaeva ${ }^{11}, \mathrm{R}$. Ivanov ${ }^{11} .{ }^{1}$ North-Western State Medical University named after I.I. Mechnikov, Saint-Petersburg; ${ }^{2}$ V.A. Nasonova Research Institute of Rheumatology, Moscow, ${ }^{3}$ N.A. Semashko N. Novgorod Regional Clinical Hospital, N. Novgorod; ${ }^{4}$ S. V. Belayev Kemerovo Regional Clinical Hospital, Kemerovo, Russian Federation; ${ }^{5}$ Clinical Hospital No1; ${ }^{6}$ Clinical Hospital No9, Minsk, Belarus; ${ }^{7}$ Rostov State Medical University, Rostov-on-Don; ${ }^{8}$ Chelyabinsk Regional Clinical Hospital, Chelyabinsk; ${ }^{9}$ Irkutsk Municipal Clinical Hospital No1, Irkutsk; ${ }^{10}$ Leningrad Region Clinical Hospital; ${ }^{11}$ JCS BIOCAD, Saint-Petersburg, Russian Federation

Background: Equivalent efficacy of BCD-055 and infliximab (INF) innovator has been previously established (the primary endpoint: ACR20 at Wk14) ${ }^{1}$.
Objectives: The impact of BCD-055 and INF innovator on RA activity has been analysed within 14 week study period. DAS28-CRP $\left({ }^{4} \mathrm{CDAl}\right.$ and SDAI were evaluated. Additionally, safety data has been collected.

Methods: The study was conducted as international multicenter randomised double-blind placebo controlled study. The study enrolled 426 adults with active RA Patients were randomised into 2 study arms in 2:1 ratio to receive BCD-055 or INF innovator in dose of $3 \mathrm{mg} / \mathrm{kg}$. In the analysed period of the study, patients received the iv infusions on Wk0, Wk2, Wk6, Wk14.

Results: Efficacy: BCD-055 and INF innovator showed similar impact on RA activity: in both groups significant decline of DAS28-CRP $\left({ }^{4}\right.$ was observed (figure 1). This result corresponds to positive CDAI and SDAI dynamics (table 2). Medians of CDAI/SDAl on screening indicated high RA activity, while on Wk $14-$ moderate activity. Analyses of inflammatory markers (ESR and C-reactive protein) revealed pronounced decline in ESR and CRP levels by Wk 2. No further elevation has been observed.

Safety: No differences in safety profiles of BCD-055 and INF innovator has been shown. One of the most frequent AEs were arterial hypertension, anaemia, neutropenia and increase of transaminases. Number of patients with binding and neutralising antibodies also did not differ between groups. Babs were detected in $6.83 \%$ patients in BCD-055 arm and in $7.81 \%$ in INF innovator arm $(p=0.888)$, Nab were observed in $1.61 \%$ and $0.78 \%$ patients in same arms $(p=0.666)$.

Abstract THU0193 - Table 1. SDAI, CDAI dynamics.

\begin{tabular}{llccc}
\hline & & Screening & Wk14 & p-value \\
\hline SDAI & BCD-055 $(n=280)$ & $42.46[35.15-$ & $16.22[8.45-$ & $<\mathbf{0 . 0 0 0 0 0}$ \\
& & $51.11]$ & $25.03]$ & \\
& INF innovator & $41.22[34.21-$ & $16.15[9.06-$ & $<\mathbf{0 . 0 0 0 0 0}$ \\
& $(n=138)$ & $47.52]$ & $27.11]$ & \\
CDAI & BCD-055 $(n=280)$ & $39.15[31.50-$ & $15.40[8.00-$ & $<0.00000$ \\
& & $46.00]$ & $24.00]$ & \\
& INF innovator & $36.85[31.90-$ & $15.55[8.30-$ & $<0.00000$ \\
& $(n=138)$ & $42.00]$ & $25.50]$ & \\
\hline
\end{tabular}

Abstract THU0193 - Table 2. Summarised safety data

\begin{tabular}{lccc}
\hline Percentage of patients with & \multicolumn{2}{c}{ Arm } & p-value \\
\cline { 2 - 3 } & $\begin{array}{l}\text { BCD-055 } \\
(\mathbf{n}=\mathbf{2 8 0})\end{array}$ & $\begin{array}{c}\text { INF innovator } \\
(\mathbf{n}=\mathbf{1 3 8})\end{array}$ & \\
\hline Any AE/SAE & $53.57 \%(150)$ & $44.93 \%(62)$ & 0.119 \\
Therapy-related AEs & $26.43 \%(74)$ & $24.64 \%{ }^{34}$ & 0.784 \\
Any SAE & $2.14 \%^{6}$ & $1.45 \%^{2}$ & 1.00 \\
Grade 3-4 AEs & $10.00 \%^{28}$ & $5.80 \%{ }^{8}$ & 0.966 \\
Therapy-related grade 3-4 AEs & $5.71 \%^{16}$ & $4.35 \%^{6}$ & 0.722 \\
Therapy-discontinuation due to AE & $2.50 \%^{7}$ & $2.90 \%{ }^{7}$ & 0.757 \\
\hline
\end{tabular}

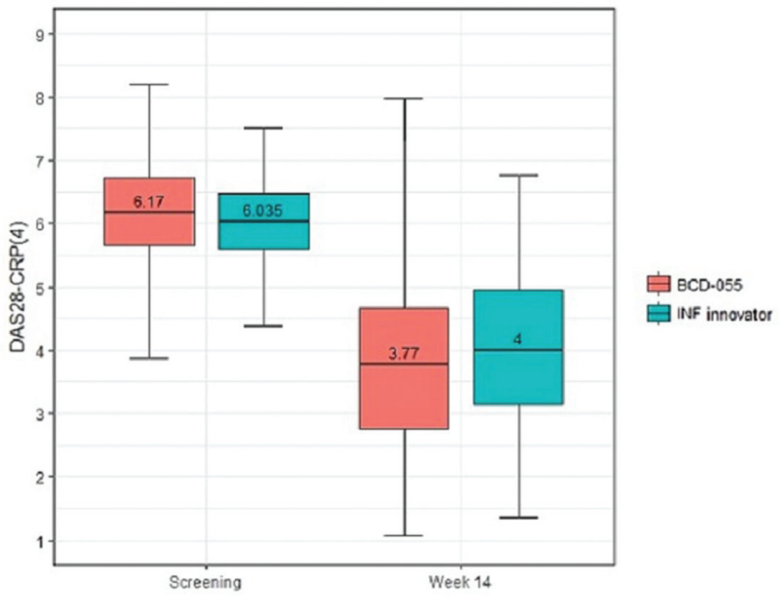

Conclusions: Treatment with BCD-055 and INF innovator leads to significant decline in RA activity and inflammatory markers by Wk14, which corresponds with previous results of ACR20 assessment1. Both drugs are well tolerated with no dif ferences in safety profiles. The frequency of ADA formation is also comparable.

\section{REFERENCE:}

[1] Denisov L, Gordeev I, Mazurov V, et al. FRI0208 Comparison of efficacy, safety and pharmacokinetics of infliximab biosimilar (BCD-055) and innovator infliximab Ann Rheum Dis 2017;76:560-561. 
Disclosure of Interest: A. Lila: None declared, L. Denisov: None declared, T. Plaksina: None declared, S. Smakotina: None declared, E. Kunder: None declared, N. Soroka: None declared, A. Kastanayan: None declared, O. Nes meyanova: None declared, O. Antipova: None declared, E. Ilivanova: None declared, A. Eremeeva Employee of: JSC BIOCAD, E. Dokukina Employee of: JSC BIOCAD, E. Chernyaeva Employee of: JSC BIOCAD, R. Ivanov Employee of: JSC BIOCAD

DOI: 10.1136/annrheumdis-2018-eular.2332

\section{THU0194 CD4+ T CELLS, IMMUNOGLOBULINS AND RISK OF INFECTION IN PATIENTS WITH RHEUMATOID ARTHRITIS OVER MULTIPLE CYCLES OF RITUXIMAB}

F. Martins ${ }^{1}$, A. Bensalem ${ }^{2}$, T. Bejan-Angoulvant ${ }^{2,3}$, A. Lhommas ${ }^{1}$, J. Mélet $^{1,2}$, S. Mammou ${ }^{1}$, G. Thibault ${ }^{2,4,5}$, L. Bernard ${ }^{6}$, P. Goupille ${ }^{1,2}$, D. Mulleman ${ }^{1,2}$. ${ }^{1}$ Rheumatology, CHRU de Tours; ${ }^{2}$ EA GICC, University of Tours; ${ }^{3}$ Clinical Pharmacology, CHRU de Tours; ${ }^{4}$ CNRS ERL 7001, University of Tours; ${ }^{5}$ Immunology, ${ }^{6}$ Infectious diseases, CHRU de Tours, Tours, France

Background: Rituximab (RTX) may be responsible for infectious event in RA patients. Immunological markers may be associated with the occurrence of infections.

Objectives: To evaluate lymphocyte counts and immunoglobulin concentrations over multiple cycles of RTX in RA patients, and to analyse the relationship between these markers and the occurrence of infections.

Methods: Retrospective monocentric study on 94 RA patients treated with RTX At baseline and during follow up, lymphocyte phenotyping (CD4+, CD3+, CD19 +cells), gammaglobulin, IgG, IgM and IgA concentration were assessed Patients were dichotomized according to the absence or presence of infectious events. A student's test was used to compare the continuous variables and a Chi2 test or the Fisher test was used for the dichotomous variables.

Results: A total of 119 infectious events occurred during follow-up, of which only 11 were serious, with respective incidences of 65 per 100 patient-years and 6 per 100 patient-years. Low IgM concentration at RTX initiation and low IgG concentration $(<5 \mathrm{~g} / \mathrm{L})$ throughout follow-up were associated with an increased risk of infection. Both gammaglobulin and IgG concentrations decreased along with successive cycles of RTX in patients with infection, while they remained stable in patients without infection. Twelve patients had a CD4 +cell count $<200 / \mathrm{mm}^{3}$ during follow up, of which one with a CD4 +cell count $233 / \mathrm{mm}^{3}$ at baseline, who subsequently presented an opportunistic infection.

Conclusions: Gammaglobulin, IgM and IgG concentrations and CD4 +cell count are valuable before RTX initiation in RA patients. IgG or gammaglobulin concentration should also be monitored before each cycle. CD4 +lymphocytes monitoring should be considered in patients with low value at initiation.

Disclosure of Interest: F. Martins: None declared, A. Bensalem: None declared, T. Bejan-Angoulvant: None declared, A. Lhommas: None declared, J. Mélet: None declared, S. Mammou: None declared, G. Thibault: None declared, L. Bernard: None declared, P. Goupille Consultant for: Abbvie, Biogaran, BMS, Hospira Janssen-Cilag, MSD, Pfizer, Sanofi-Genzyme and UCB, D. Mulleman Grant/ research support from: Abbvie and Nordic Pharma, Consultant for: MSD, Novartis, UCB and Pfizer

DOI: 10.1136/annrheumdis-2018-eular.7030

\section{THU0195 \\ PREVALENCE OF OCCULT HEPATITIS B CARRIER STATUS AND ITS ASSOCIATED FACTORS IN PATIENTS WITH RHEUMATIC DISEASES UNDERGOING BIOLOGICAL THERAPIES}

C.C. Mok ${ }^{1}$, L.Y. Ho ${ }^{1}$, K.L. Chan ${ }^{1}$, S.M. Tse ${ }^{1}$, C.H. To ${ }^{2} .{ }^{1}$ Medicine, Tuen Mun Hospital; ${ }^{2}$ Medicine, Pok Oi Hospital, HK, Hong Kong

Objectives: To study the prevalence of occult hepatitis B carrier status and its associated factors in patients with rheumatic diseases undergoing biological therapies

Methods: Consecutive adult patients with various rheumatic diseases who were currently receiving biological therapies between November 2016 and April 2017 were recruited in this cross-sectional study. Blood was taken for evidence of hepatitis B infection ( $\mathrm{HBsAg}$, anti-HBs, anti-HBc-lgG). For patients tested positive for $\mathrm{HBsAg}$ or anti-HBc-lgG, assay of serum HBV-DNA level was also performed. Occult hepatitis $B$ carrier was defined as patients who were $\mathrm{HBs} A g$ negative but anti-HBc-lgG positive. Logistic regression was performed to study factors independently associated with occult hepatitis $B$ carrier status in these patients.

Results: 310 Chinese patients were studied $(60 \%$ women, age at biological therapy $44.0 \pm 13.0$ years). The underlying rheumatic diseases requiring biological therapies were rheumatoid arthritis $(46 \%)$, spondyloarthritis $(31 \%)$, psoriatic arthritis (12\%) and systemic lupus erythematosus (8.1\%). The biologics being used were the TNF inhibitors $(66 \%)$, tocilizumab $(16 \%)$, abatacept $(2.9 \%)$, rituximab $(7.7 \%)$, belimumab (5.8\%) and tofactinib (1.3\%). Hepatitis B carrier (HBsAg +) status was detected in $11(3.5 \%)$ patients and they were all put on preemptive anti-viral therapy (entecavir). A total of 105 patients (34\%) were occult hepatitis $B$ carriers (HBsAg- but anti-HBc-lgG+). Anti-HBs was present in 83/105 (79\%) of these patients. Occult hepatitis $B$ carriers were significantly older than the non carriers ( $49.9 \pm 11.1$ vs $40.9 \pm 13.3$ years; $p<0.001)$, and were more frequently identified in rheumatoid arthritis than other rheumatic diseases $(45 \%$ vs $25 \%$; $\mathrm{p}<0.001)$. However, there was no gender difference in the prevalence of the occult hepatitis $B$ carrier status ( $37 \%$ in women vs $28 \%$ in men; $p=0.10$ ). Logistic regression revealed that older age (RR 1.05 [1.03-1.08] per year; $p<0.001)$ was the only independent factor significantly associated with occult hepatitis B infection. Rheumatoid arthritis was not significantly associated with occult hepatitis B carrier status after adjustment for age and sex. Of the occult hepatitis B carriers, $9(8.6 \%)$ had detectable HBV-DNA levels but all were very low titers $(<100 \mathrm{lU} / \mathrm{ml})$. Five (56\%) patients with detectable HBV-DNA levels received entecavir treatment during biological therapies, while $19(20 \%)$ patients without detectable HBV-DNA were put on preemptive entecavir treatment (including all patients who were receiving rituximab). None of the overt $(\mathrm{HBsAg}+)$ or occult hepatitis $\mathrm{B}(\mathrm{HBsAg}$ anti-HBc-lgG+) carrier patients developed clinical reactivation of hepatitis $B$ during a mean of $5.0 \pm 3.7$ years of biological therapies.

Conclusions: Occult hepatitis B carrier status was present in one-third of Hong Kong Chinese patients with various rheumatic diseases undergoing biological therapies. Older age was the only independent factor associated with occult hepatitis $B$ infection. Despite the relatively low rate of preemptive anti-viral treatment in these patients, clinical reactivation of hepatitis B was not reported over 5 years of biological therapies.

Disclosure of Interest: None declared

DOI: 10.1136/annrheumdis-2018-eular.4333

\section{THU0196 \\ DO CONTEXTUAL FACTORS INFLUENCE SURVIVAL ONDRUG OF BIOSIMILARS IN CLINICAL PRACTICE?}

D. Di Giuseppe ${ }^{1}$, T. Frisell ${ }^{2}$, E. Lindqvist ${ }^{3}$, L. Jacobsson ${ }^{4}$, C. Turesson ${ }^{3}$, C. Sjöwall ${ }^{5}$, J. Askling ${ }^{1}$, on behalf of ARTIS group. ${ }^{1}$ Department of MedicineSolna, Karolinska Institutet, ${ }^{2}$ Department of MedicineSolna, SRQ, Stockholm; ${ }^{3}$ Lund University and Skåne University Hospital, Malmö; ${ }^{4}$ Sahlgrenska Academy, University of Gothenburg, Gothenburg; ${ }^{5}$ Linköping University, Linköping, Sweden

Background: The introduction of biosimilars has been linked to concerns regarding their effectiveness and safety compared to their originator products. Whilst randomized controlled trials may address their relative efficacy, the outcome of biosimilars in clinical practice may be influenced by contextual factors, such as the treating rheumatology unit's experience with biosimilars and non-medical switching.

Objectives: To analyze whether contextual factors, such as department size and use of biosimilars, and calendar period of treatment start, influence time until treatment discontinuation (i.e. drugsurvival) of biosimilars as compared to corresponding originator products.

Methods: We used data from the Swedish Rheumatology Quality register to identify all patients with rheumatoidarthritis, ankylosing spondylitis, psoriatic arthritis, or other spondyloarthropathies who started infliximab between March 1st 2015 and Sept 30th 2017 or etanercept between April 1st 2016 and Sept 30th 2017, as their firstever biologic. Kaplan-Meier curves and Cox models were used to assess the association between drug survival and the size of the rheumatology unit, itsuse of biosimilars (extent of biosimilar use above/below national median a teach time point), and whether the treatment start occurred soon after biosimilar introduction (infliximab: first 12 months, etanercept: 6 months counting from first date of availability of the biosimilar in question). To avoid artefacts, patients were censored if switching from the originator to a biosimilar (or vice versa).

Results: During the study period, 368 and 738 patients started infliximab originator or biosimilar, and 125 and 2079 started etanercept originator or biosimilar, as first ever biological treatment. Overall, the hazard ratio $(\mathrm{HR})$ of discontinuing treatment (comparing the biosimilar vs its originator) was 1.21 (95\% Cl: $0.96-1.51)$ for infliximab and 0.88 (95\% Cl: $0.57-1.35)$ for etanercept, adjusted for indication age(quartiles), gender, region, and HAQ (quartiles), DAS28 (quartiles) and globalhealth (quartiles) at treatment start. Patients treated in large clinics (more than 1695 patients (75th percentile) at the end of the study period) were at a lower risk of drug discontinuation (table 1). We noted no association between overall biosimilar use in the rheumatology clinic in question and survival on drug (neither originator nor biosimilar). By contrast, those who started infliximab biosimilar later had a lower risk of discontinuing (HR: 0.65 (95\% Cl:0.50-0.85)) compared to those who started in the first year of availability. For etanercept biosimilar, no such association was noted. 